\title{
Factors Affecting Sleep Quality of Patients in Intensive Care Unit
}

\author{
Shailesh Bihari, M.D.'; R. Doug McEvoy, M.D. 2,4; Elisha Matheson, B.Nurs. '; Susan Kim, Ph.D.; ;ichard J. Woodman, Ph.D.3;
} Andrew D. Bersten, M.D. ${ }^{1}$

${ }^{1}$ Department of Intensive and Critical Care Medicine, Flinders Medical Centre, Bedford Park South Australia, Australia; ${ }^{2}$ Adelaide Institute for Sleep Health, Repatriation General Hospital, Daw Park, South Australia, Australia; ${ }^{3}$ Flinders Centre for Epidemiology and Biostatistics, Discipline of General Practice, Flinders University, South Australia, Australia; ${ }^{4}$ Flinders Centre for Clinical Change and Health Care Research, Flinders University, South Australia, Australia

Introduction: Sleep disturbance is a frequently overlooked complication of intensive care unit (ICU) stay.

Aim: To evaluate sleep quality among patients admitted to ICU and investigate environmental and non-environmental factors that affect sleep quality in ICU.

Methods: Over a 22-month period, we consecutively recruited patients who spent $\geq 2$ nights post-endotracheal extubation in ICU and who were orientated to time, place, and person on the day of discharge. Self-reported sleep quality, according to a modified Freedman questionnaire, which provided data on self-reported ICU sleep quality in ICU and environmental factors affecting sleep quality in the ICU, were collected. We also investigated non-environmental factors, such as severity of illness, ICU interventions, and medications that can affect sleep quality.

Results: Fifty males and 50 females were recruited with a mean $( \pm S D)$ age of $65.1 \pm 15.2$ years. APACHE II score at admission to ICU was $18.1 \pm 7.5$ with duration of stay $6.7 \pm$ 6.5 days. Self-reported sleep quality score at home $(1=$ worst; $10=$ best) was $7.0 \pm 2.2$; this decreased to $4.0 \pm 1.7$ during their stay in ICU $(p<0.001)$. In multivariate analysis with APACHE III as severity of illness $\left(R^{2}=0.25\right)$, factors $[\exp (b)(95 \% \mathrm{Cl})$, $p$ value] which significantly affected sleep in ICU were sex [0.37(0.19-0.72), $p<0.01]$, age and sex interaction [1.02(1.01$1.03), p<0.01]$, bedside phone [0.92(0.87-0.97), $p<0.01]$, prior quality of sleep at home [1.30(1.05-1.62), $p=0.02]$, and use of steroids [0.82(0.69-0.98), $p=0.03]$ during the stay in ICU.

Conclusion: Reduced sleep quality is a common problem in ICU with a multifactorial etiology.

Keywords: Intensive care unit, sleep questionnaire, sleep quality, factors affecting sleep

Citation: Bihari S; McEvoy RD; Kim S; Woodman RJ; Bersten $A D$. Factors affecting sleep quality of patients in intensive care unit. J Clin Sleep Med 2012;8(3):301-307. frequently overlooked complication of intensive care unit (ICU) admission is a lack of adequate sleep. In critically ill patients the prevalence of sleep disturbance has been shown to be more than $50 \% .{ }^{1}$ Disrupted sleep is associated with immune system dysfunction, impaired resistance to infection, alterations in nitrogen balance, impaired wound healing, and cardiorespiratory and neurological consequences. ${ }^{2}$ Several polysomnographic studies have demonstrated decreased total sleep time, sleep fragmentation, and altered sleep architecture in patients in ICU. ${ }^{3-10}$ When examining the etiologies of sleep disturbance, these studies have focused on environmental stimuli such as increased noise. ${ }^{11}$ However, increased ICU noise level as the sole cause of sleep deprivation has been questioned. ${ }^{12-14}$ Frequent interruptions for diagnostic tests and routine patient care may also cause frequent arousals from sleep. ${ }^{1,2}$

In addition to environmental causes of poor sleep, sleep disturbance may also be related to non-environmental factors, including the condition at presentation (e.g., chronic obstructive pulmonary disease, pulmonary edema, myocardial infarction, postoperative state), disease or illness severity, patient discomfort, ${ }^{2,4,5,10,15,16}$ patient medications (home medications) prior to admission, particularly those prescribed for insomnia and anxiety or depression, ICU interventions such as ventilators (invasive and noninvasive), dialysis, intra-aortic balloon counter pulsation (IABP) and the drugs administered in ICU. We there-

\section{BRIEF SUMMARY}

Current Knowledge/Study Rationale: Environmental factors are known to affect quality of sleep in ICU.

Study Impact: In addition to previously established environmental factors, several non-environmental factors were identified which were associated with self-reported poor quality sleep in ICU.

fore aimed to examine the effects of these non-environmental factors on sleep quality in ICU in addition to the already established environmental factors.

\section{METHODOLOGY}

\section{Study Design and Location}

A cross-sectional study using a recall questionnaire was conducted on patients admitted to the Flinders Medical Centre (FMC) Intensive Care Unit (ICU). FMC is a University teaching hospital and its ICU a 32-bed tertiary level adult medical and surgical unit. There are over 2200 medical, surgical, trauma, and post-cardiovascular surgical admissions per year. There is a dedicated room for each bed and a 1:1 nursing ratio for all ventilated patients. Personal mobile phones are blocked in ICU, but most of the doctors carry a digital enhanced cordless telecommunications (DECT) phone and/or a pager. Land line phones are locat- 
Figure 1-Sleep questionnaire

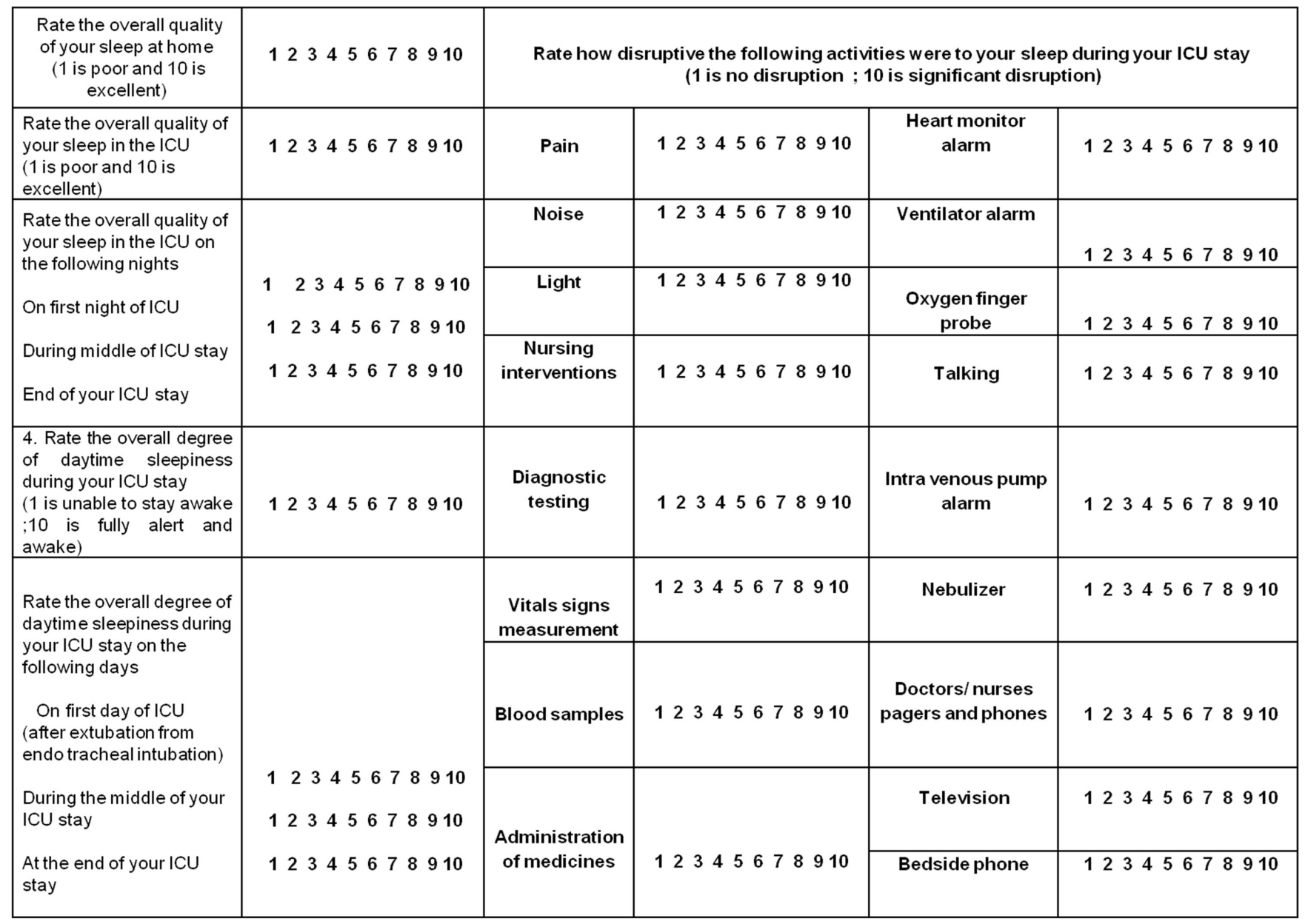

The questionnaire utilized in the study. Modified from Freedman et al. ${ }^{12}$

ed in every patient bed and in the central nursing station, which overlooks the patient bays. Each ICU bay has a central monitor, which monitors patients heart rate, blood pressure (both invasive and noninvasive), respiratory rate, oxygen saturation, and various other vital parameters depending upon the patient's illness and its severity. There are various machines present in the patient's bay, such as a mechanical ventilator, dialysis machines, and nebulizers, according to the patient's requirement. Each patient is rolled every couple of hours to prevent development of pressure areas. Patients are also given a wash early in the morning before the nurse's handover at 07:00.

\section{Subject Recruitment, Inclusion, and Exclusion Criteria}

Inclusion criteria were: patients admitted to ICU for $\geq 2$ nights ( $\geq 2$ nights post extubation from endotracheal intubation) who were orientated to time, place, and person at discharge when the survey was performed. All ICU patients discharged between March 2009 and December 2010 were eligible to participate in the study; patients with moderate to severe dementia and patients who declined to provide consent were excluded. Patients receiving noninvasive mechanical ventilation or tracheostomy at the time of discharge were not excluded. Potential participants were consecutively screened every morning Monday to Friday from 08:00 to 12:00 at the time of discharge from ICU.
The study was approved by the committee on human research at Flinders Medical Centre, South Australia, and written consent was given by all subjects.

\section{Sleep Questionnaire}

Patients were asked to complete a modified ICU quality of sleep questionnaire developed by Freedman et al. ${ }^{12}$ (Figure 1). The Freedman questionnaire collects data on a variety of environmental factors known to affect sleep quality. We modified the questionnaire to include pain, as pain can also affect sleep quality in ICU. The questionnaire requires participants to retrospectively rate their overall quality of sleep on a 10-point scale ranging from 1 (worst possible) to 10 (best possible) (a) at home in the weeks and months before their admission to the ICU; (b) averaged across their whole ICU admission; and (c) on the first day, the midpoint, and the end of their ICU stay. Participants were also ask to rate their day time sleepiness $(1=$ unable to stay awake; $10=$ fully alert) averaged across their whole ICU admission and on the first day, the midpoint, and the end of their ICU stay. Participants were then asked to rate on a 10-point scale to what extent they considered various environmental factors caused their sleep to be disrupted $(1=$ no disruption and $10=$ significant disruption $)$. It took approximately 10 minutes for the participant to fill out the questionnaire. If they were unable to fill out the questionnaire because 
of muscle weakness, poor eyesight, or tracheotomy, the questionnaire was read aloud to them and their responses were recorded.

\section{Demographic and Clinical Data}

Data were collected on age at admission, sex, principal diagnosis, length of stay in ICU, length of hospital stay, requirement for intubation, APACHE II and APACHE III score at admission, postoperative state, dialysis, IABP, noninvasive ventilation (NIV), treatment of hypo- and hyperthyroidism, intravenous magnesium administration, inotropes, steroids, $\beta$-blockers, antipsychotics, diuretics, benzodiazepine (BZD), regular opioids, anti-anxiety, anti-depressant drugs, and sleeping tablets in ICU. Past history of regular use of sleeping tablets, antidepressants, antipsychotics, or anti-mania drugs was also recorded. These data were collected on the day of the discharge of the patients from their clinical notes and ICU charts. Data regarding the length of ICU and hospital stay was recorded from the ICU database at a later date. The whole data collection approximately took 15 min per patient.

Dementia status was assessed using the global clinical dementia rating score (CDR). ${ }^{17}$ This is a clinical staging instrument for dementia. It characterizes 6 domains of cognitive and functional performance: memory, orientation, judgment and problem solving, community affairs, home and hobbies, and personal care. The necessary information to make each rating was obtained through a semi-structured interview of the patient plus a reliable informant or collateral source. Patients with a CDR score $>2$ were excluded.

\section{Statistical Analysis}

Data were analyzed using Stata version 11.0 (Statacorp, Texas, USA). Quality of sleep in the ICU (first, mid, end and overall), quality of sleep at home, and daytime sleepiness were log-transformed. Mixed effects linear regression (Stata xtmixed command) was used to assess whether the quality of sleep was different at different time points (home; first, middle, and end of stay in the ICU; and ICU overall, used as a categorical variable from 1-5) with the patient as a random effect (random intercept). A linear regression model (Stata regress command) was used to examine the effect of length of stay on the quality of sleep and the daytime sleepiness.

Generalized linear model (Stata glm command) was used to assess factors affecting the quality of sleep in the ICU. In univariate analysis, the 43 variables listed in Table 1 were individually assessed as predictors of the quality of sleep in the ICU. Variables significant at $\alpha=0.10$ level were then assessed for possible inclusion in multivariate regression. For the multivariate regression, age, sex, and severity of illness (APACHE II, APACHE III, or SAPS II) were included in the model regardless of their significance. The interaction between age and sex on sleep quality was also examined. A type 1 error rate of $\alpha=0.05$ was considered statistically significant. The goodness of fit was assessed using the QQ plot of standardized residuals.

All descriptive data are presented as mean \pm SD unless otherwise stated.

\section{RESULTS}

A total of 148 patients were screened on their day of discharge from ICU. Forty-eight patients were excluded (24 de-
Table 1-Variables examined in univariate analysis as predictors of quality of sleep in ICU

\begin{tabular}{|c|c|c|}
\hline $\begin{array}{l}\text { Patient characteristics and } \\
\text { non-environmental factors }\end{array}$ & $\operatorname{Exp}(b)(95 \% \mathrm{Cl})$ & p-value \\
\hline Age & $1.00(1.00,1.01)$ & 0.11 \\
\hline Sex & $1.02(0.84,1.23)$ & 0.86 \\
\hline APACHE II & $1.00(0.99,1.01)$ & 0.81 \\
\hline APACHE III & $1.00(1.00,1.00)$ & 0.97 \\
\hline SAPS2 & $1.00(0.99,1.01)$ & 0.82 \\
\hline $\begin{array}{l}\text { History of requirement of } \\
\text { regular sleeping tablet }\end{array}$ & $0.84(0.70,1.01)$ & 0.07 \\
\hline Endotracheal intubation & $0.89(0.74,1.07)$ & 0.21 \\
\hline Postoperative state & $1.05(0.86,1.28)$ & 0.62 \\
\hline Dialysis & $0.86(0.68,1.09)$ & 0.23 \\
\hline IABP & $0.92(0.67,1.25)$ & 0.59 \\
\hline Other sleeping tablets & $0.86(0.71,1.03)$ & 0.11 \\
\hline Pain & $1.02(0.98,1.07)$ & 0.31 \\
\hline Length of ICU stay & $1.00(0.98,1.01)$ & 0.71 \\
\hline Daytime sleepiness & $0.88(0.71,1.10)$ & 0.27 \\
\hline Noninvasive ventilator & $1.11(0.92,1.34)$ & 0.27 \\
\hline Hypo- or hyperthyroid treatment & $0.83(0.66,1.04)$ & 0.10 \\
\hline Magnesium administration & $0.99(0.82,1.2)$ & 0.91 \\
\hline Inotropes & $0.90(0.75,1.09)$ & 0.29 \\
\hline Steroids & $0.84(0.70,1.02)$ & 0.07 \\
\hline$\beta$-blockers & $1.11(0.89,1.38)$ & 0.37 \\
\hline Antipsychotic & $0.84(0.66,1.09)$ & 0.19 \\
\hline Diuretics & $0.94(0.78,1.14)$ & 0.54 \\
\hline Benzodiazepine & $0.79(0.63,0.99)$ & 0.04 \\
\hline Opioids & $1.03(0.84,1.26)$ & 0.76 \\
\hline $\begin{array}{l}\text { Other anti-anxiety/ } \\
\text { depressant drugs }\end{array}$ & $0.86(0.67,1.11)$ & 0.24 \\
\hline Length of hospital stay & $1.00(0.99978,1.0001)$ & 0.50 \\
\hline Quality of sleep at home & $1.32(1.04,1.67)$ & 0.02 \\
\hline \multicolumn{3}{|l|}{ Environmental factors } \\
\hline Noise & $0.99(0.95,1.03)$ & 0.53 \\
\hline Light & $0.98(0.94,1.02)$ & 0.31 \\
\hline Nursing intervention & $1.02(0.98,1.07)$ & 0.39 \\
\hline Diagnostic testing & $1.03(0.98,1.07)$ & 0.26 \\
\hline Vital sign measurement & $1.02(0.96,1.07)$ & 0.52 \\
\hline Phlebotomy & $1.03(0.97,1.08)$ & 0.33 \\
\hline Administration of medicines & $1.00(0.95,1.05)$ & 0.96 \\
\hline Heart monitor alarm & $0.99(0.95,1.03)$ & 0.62 \\
\hline Pulse oximeter & $0.99(0.95,1.04)$ & 0.80 \\
\hline Talking & $0.99(0.96,1.03)$ & 0.67 \\
\hline Intravenous pump alarm & $0.95(0.91,1.00)$ & 0.05 \\
\hline Nebulizer & $0.97(0.92,1.02)$ & 0.21 \\
\hline $\begin{array}{l}\text { Doctors \& nurses: phone and } \\
\text { pagers }\end{array}$ & $0.99(0.94,1.04)$ & 0.76 \\
\hline Television & $0.92(0.86,0.99)$ & 0.03 \\
\hline Bedside phone & $0.93(0.88,0.99)$ & 0.02 \\
\hline Ventilator alarm & $0.99(0.95,1.04)$ & 0.68 \\
\hline
\end{tabular}

nied consent for the study and 24 patients had $C D R \geq 2$ ) leaving 100 patients who completed the questionnaire. Mean $( \pm$ SD) patient age was $63.2 \pm 16.7$ years. APACHE II and APACHE 
Figure 2-Mean perceived level of disruption of sleep quality from various ICU activities

\section{Disruption in sleep}

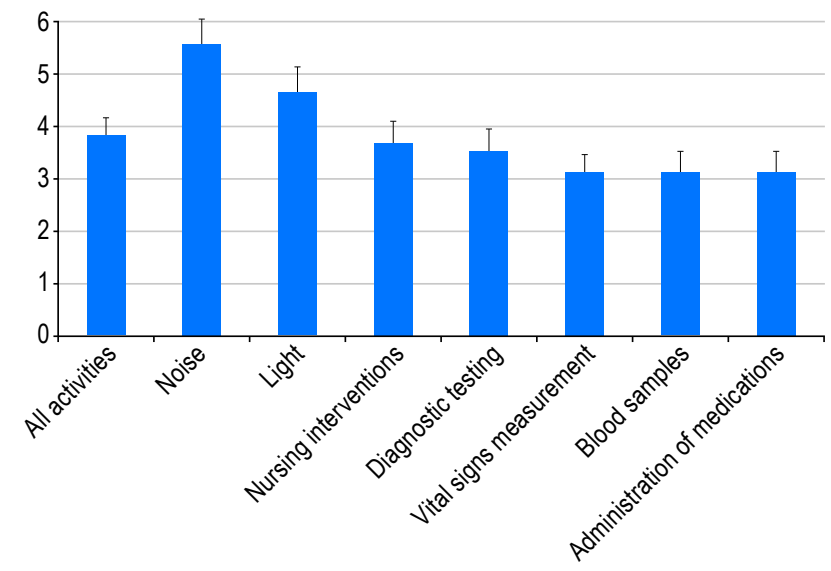

$1=$ no disruption to $10=$ significant disruption. Bars represent upper $95 \%$ confidence limits.

Table 2-Frequency of ICU interventions and medications $(n=100)$

$\begin{array}{lc}\text { Medication } & \text { Subjects (\%) } \\ \text { Steroids } & 40 \\ \text { B-blockers } & 23 \\ \text { Antipsychotic } & 16 \\ \text { Diuretics } & 61 \\ \text { Benzodiazepine } & 21 \\ \text { Regular opioids } & 32 \\ \text { Other anti-anxiety/antidepressant drugs } & 16 \\ \text { Other sleeping tablets } & 44 \\ \text { Antiepileptic } & 18 \\ \text { Magnesium administration } & 63 \\ \text { Inotropes } & 61 \\ \text { Hypo- or hyperthyroidism treatment } & 22 \\ \text { History of use of regular sleeping tablets, } & 39 \\ \text { antidepressants, antipsychotics, or anti-mania } & \\ \text { drugs at home } & \\ \text { Interventions } & \\ \text { Endotracheal intubation } & \\ \text { Postoperative } & 54 \\ \text { Dialysis } & 35 \\ \text { Intra-aortic balloon pump } & 19 \\ \text { Noninvasive ventilator } & 10 \\ & \end{array}$

III scores at admission to ICU were $18.1 \pm 7.5$ and $59.3 \pm 24.9$, respectively. Duration of stay in ICU was $6.7 \pm 6.5$ days, and duration of stay in hospital was $23.4 \pm 24.0$ days.

Of all the total discharges (3199 patients) during this time period of study mean $( \pm$ SD) APACHE II and APACHE III scores at admission to ICU were $18.5 \pm 7.6$ and $65.6 \pm 28.2$, respectively, and duration of stay in ICU was $6.1 \pm 9.5$ days.

\section{Sleep Quality and Daytime Sleepiness}

Self-reported quality of sleep decreased from $7.03 \pm 2.2$ at home to $4.0 \pm 1.7$ during their stay in ICU $(p<0.001)$. The
Figure 3-Mean perceived disruption in sleep quality from various sources of noise

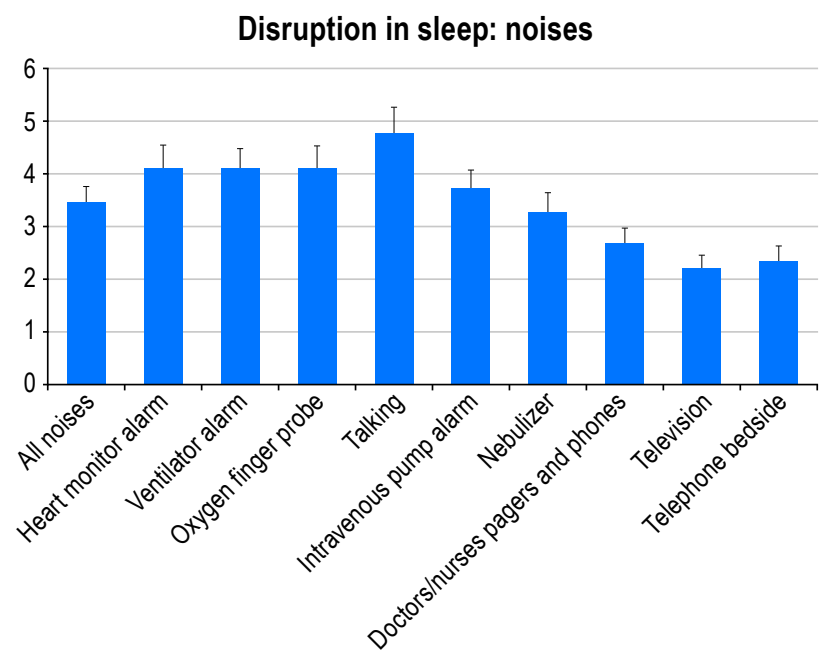

Disruptions rated on a scale of $1=$ no disruption to $10=$ significant disruption. Bars represent upper $95 \%$ confidence limits.

daytime sleepiness score among subjects during their ICU stay was $5.0 \pm 1.4$. Twenty-six percent of patients rated their daytime sleepiness from 1 to 3; 53\% rated it between 4 and 6 ; and $21 \%$ rated it $\geq 7$. Quality of sleep or daytime sleepiness did not change significantly over the course of any patient's ICU stay. Neither quality nor perceived daytime sleepiness was significantly affected by the length of stay in the ICU $(p>0.05)$.

\section{Factors Affecting Sleep Quality}

Multiple environmental factors and noises were reported to disrupt sleep (Figures $\mathbf{2}$ and $\mathbf{3}$ ). The frequency of interventions and medications that affected sleep quality is listed in Table $\mathbf{2}$. In univariate analysis, the non-environmental factors significantly associated with sleep quality in ICU were quality of sleep at home $(\mathrm{p}=0.02)$, use of regular sleeping tablets before ICU $(p=0.07)$, treatment for hypo-/hyperthyroidism $(p=0.10)$, use of both benzodiazepines $(p=0.04)$ and steroids $(p=0.07)$ during the ICU stay, and environmental factors such as noise from intravenous pump alarms $(p=0.05)$, televisions $(p=0.03)$, and bedside telephones $(p=0.02)$ (Table 1). We examined the effect of vasoactive drugs individually and as a class of drugs and did not find any association with sleep quality.

Spearman correlation coefficients were calculated to examine the correlations among various noise sources and also the correlations among various ICU activities. Nursing intervention, diagnostic testing, vital sign measurement, blood samples, and administration of medicines were significantly positively correlated ( $r$ between 0.58 and $0.75, \mathrm{p}<0.01$ ). Doctors and nurses' phone and pagers, bedside phone, and television were significantly positively correlated ( $r$ between 0.59 and $0.70, p<0.01$ ), only one of these activities and the noise source that gave the strongest effect were included in the final multiple regression model.

In multivariate analysis with APACHE III as severity of illness $\left(\mathrm{R}^{2}=0.25\right)$, factors $[\exp (\mathrm{b})(95 \% \mathrm{CI}), \mathrm{p}$ value] which significantly affected sleep in ICU were sex [0.37(0.19-0.72), p < 0.01], age and sex interaction [1.02(1.01-1.03), $\mathrm{p}<0.01]$, bedside 
Table 3-Multivariate analysis of perceived sleep quality in the ICU

\begin{tabular}{lccc} 
& \multicolumn{3}{c}{ Model with APACHE II (adjusted $\left.\mathbf{R}^{2}=\mathbf{0 . 2 5}\right)$} \\
\cline { 2 - 4 } Age & $\operatorname{Exp}(\mathbf{b})(95 \% \mathrm{Cl})$ & Change in adjusted $\mathbf{R}^{2}$ & p-value \\
Sex & $1.00(0.99-1.00)$ & & 0.386 \\
Sex Age & $0.37(0.19-0.72)$ & -0.01 & 0.004 \\
Bedside phone & $1.02(1.01-1.03)$ & 0.09 & 0.002 \\
Quality of sleep at home & $0.92(0.87-0.97)$ & 0.05 & 0.002 \\
Steroids & $1.31(1.05-1.63)$ & 0.06 & 0.016 \\
Benzodiazepine & $0.82(0.69-0.98)$ & 0.03 & 0.029 \\
APACHE II & $0.84(0.68-1.02)$ & 0.02 & 0.084 \\
APACHE II & $1.00(0.98-1.01)$ & -0.01 & 0.637
\end{tabular}

Model with SAPS2 (adjusted $\left.\mathrm{R}^{2}=\mathbf{0 . 2 5}\right)$

$\begin{array}{llll}\text { Age } & 1.00(0.99-1.00) & & 0.34 \\ \text { Sex } & 0.38(0.19-0.74) & -0.01 & 0.005 \\ \text { Sex*Age } & 1.02(1.01-1.03) & 0.09 & 0.002 \\ \text { Bedside phone } & 0.92(0.87-0.97) & 0.05 & 0.002 \\ \text { Quality of sleep at home } & 1.31(1.05-1.63) & 0.06 & 0.016 \\ \text { Steroids } & 0.82(0.69-0.98) & 0.03 & 0.026 \\ \text { Benzodiazepine } & 0.83(0.68-1.02) & 0.02 & 0.073 \\ \text { SAPS2 } & 1.00(0.99-1) & -0.01 & 0.743\end{array}$

Model with APACHE III (adjusted $\mathrm{R}^{2}=\mathbf{0 . 2 5}$ )

$\begin{array}{lcc}\operatorname{Exp}(\mathbf{b})(95 \% \mathrm{Cl}) & \text { Change in adjusted } \mathbf{R}^{2} & \mathbf{p} \text {-value } \\ 1.00(0.99-1.00) & & 0.378 \\ 0.37(0.19-0.72) & -0.01 & 0.004 \\ 1.02(1.01-1.03) & 0.09 & 0.001 \\ 0.92(0.87-0.97) & 0.05 & 0.001 \\ 1.3(1.05-1.62) & 0.06 & 0.018 \\ 0.82(0.69-0.98) & 0.03 & 0.026 \\ 0.83(0.68-1.02) & 0.02 & 0.079 \\ & & \\ 1.00(1-1) & 0.00 & 0.483\end{array}$

\begin{tabular}{|c|c|c|}
\hline \multicolumn{3}{|c|}{ Model without severity of illness (adjusted $R^{2}=0.25$ ) } \\
\hline $\operatorname{Exp}(\mathrm{b})(95 \% \mathrm{Cl})$ & Change in adjusted $R^{2}$ & $p$-value \\
\hline $1.00(0.99-1.00)$ & & 0.277 \\
\hline $0.37(0.19-0.71)$ & -0.01 & 0.003 \\
\hline $1.02(1.01-1.03)$ & 0.09 & 0.001 \\
\hline $0.92(0.87-0.97)$ & 0.05 & 0.001 \\
\hline $1.31(1.06-1.62)$ & 0.06 & 0.014 \\
\hline $0.82(0.69-0.97)$ & 0.03 & 0.02 \\
\hline $0.83(0.68-1.01)$ & 0.02 & 0.068 \\
\hline
\end{tabular}

phone [0.92(0.87-0.97), $\mathrm{p}<0.01]$, prior quality of sleep at home [1.30(1.05-1.62), $\mathrm{p}=0.02]$, and use of drugs such as steroids $[0.82(0.69-0.98), p=0.03]$ during the stay in ICU (Table 3). Age [1.00 (0.99-1.00), $p=0.38]$, APACHE III [1.00(1.00-1.00), $\mathrm{p}=0.483]$, and benzodiazepines [0.83(0.68-1.02), $\mathrm{p}=0.08]$ during the stay in the ICU were not significant but included in the model. The model with different severity of illness score such as APACHE III and SAPS II and without the severity of illness score were also examined and are shown in Table 3.

We found that female subjects had an improvement in sleep with increasing age, while there was no difference in male subjects. This interaction of age and sex is shown in Figure 4. There was no effect of quality of sleep on length of stay in ICU and length of hospital stay $(\mathrm{p}>0.05)$.

\section{DISCUSSION}

Consistent with previous studies, ${ }^{12,14}$ we observed that patients admitted to ICU experienced much poorer sleep quality compared to that at home. The majority of patients also had daytime sleepiness consistent with a lack of sleep overnight. Compared to previous studies we studied a broader range of factors that could potentially affect sleep quality. In addition to examining commonly studied environmental factors as reported, for example, by Freedman et al., ${ }^{12}$ our analysis also examined the effect of non-environmental factors such as illness severity, ICU interventions (intubation, dialysis, noninvasive ventilator, postoperative status), length of ICU stay, pain, the presence of thyroid related problems, and medications used during the ICU stay. We also studied how a history of regular sleeping tablet use before ICU admission influenced self-reported sleep dur-
Figure 4-Graph showing the interaction of age and sex with sleep quality in ICU

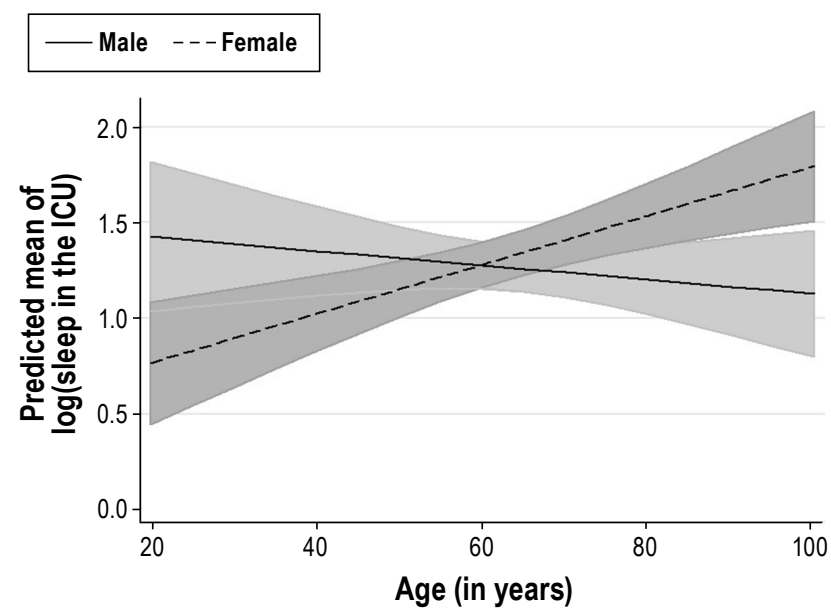

There was no effect in males of increasing age in sleep quality in ICU, while in female subjects, quality of sleep increased with increasing age. The shaded lines represent $95 \%$ confidence interval.

ing the stay in ICU. We considered it important to study these clinical factors together with environmental factors if we were to get a full picture of the likely origins of sleep disturbance in the ICU. To the best of our knowledge this is the first paper to assess both environmental and non-environmental factors together affecting sleep quality of patients in the intensive care unit. In our multivariate analysis model, we found both nonenvironmental and environmental factors impacted sleep during patients' ICU stay. 
Our results also demonstrated that perceived sleep quality does not improve over the course of ICU stay. Our results are consistent with polysomnographic studies showing that between $40 \%$ and $50 \%$ of total sleep time in an ICU occurs during the day and that sleep quality does not improve over the course of a patient's ICU stay. It has been shown that sleep may take several days to normalize after transfer of the patient to a general hospital ward. ${ }^{5,6,9,10}$

Among non-environmental factors, self-reported quality of sleep at home prior to the ICU admission was strongly associated with ICU sleep quality. Almost $40 \%$ of patients were receiving medications in the form of regular sleeping tablets, antidepressants, or antipsychotic or anti-mania drugs before being admitted to ICU. This potentially underlines the importance of continuing patients' normal sleep medications during their time in ICU (if not medically contraindicated). Patients receiving these medications prior to their acute illness generally slept poorly in ICU. Sudden discontinuation of chronic benzodiazepine hypnotic use is well known to result in rebound insomnia. Particular attention to providing a "sleep-friendly" environment to ICU patients with a history of prior insomnia or sleeping difficulties should be a part of good ICU practice. Similarly, patients with hypo- or hyperthyroidism were observed to sleep poorly in ICU and should therefore be monitored closely for their sleep quality.

The effect of drugs such as steroids and benzodiazepines on sleep is well known but has not been studied in the ICU environment. Patients receiving these drugs in ICU should be specially monitored for the quality of their sleep. Both corticosteroids and benzodiazepines and their withdrawal have been known to affect sleep architecture and decrease sleep quality. Corticosteroids have been known to decrease REM sleep and slow wave sleep and increase wakefulness and stage 2 NREM sleep. ${ }^{18,19}$ Benzodiazepines are known to decrease wakefulness, REM sleep, slow wave sleep, and sleep latency while increasing total sleep time and stage 2 sleep. ${ }^{20,21}$ The requirement for benzodiazepines is also a marker for agitation, which can cause poor sleep quality in ICU.

We observed that older patients slept better in the ICU than younger patients. This is in contrast to previous studies in which older people were found to be more readily aroused from sleep than younger individuals. ${ }^{22,23}$ However, older patients did not receive more sedatives and narcotics or more anaesthetic drugs, excluding these as possible confounders. Whether or not the ICU environment is specifically responsible for this finding requires further investigation. When subjects were divided into males and females (Figure 4), we found that female subjects had an improvement in sleep with increasing age while there was no difference in male subjects. It is known that older female subjects have more slow wave sleep than male subjects, and this may explain the age and gender interaction effects that we found. ${ }^{24}$

Surprisingly, severity (APACHE II, APACHE III score) or type of illness, length of stay in ICU, postoperative status, and ICU interventions were not associated with sleep quality in ICU. One possible explanation for this could be the use of anesthetic drugs in patients who require multiple invasive interventions, which may affect the recall potential of these subjects.

The negative effects of noise ${ }^{11}$ (particularly telephone noise) on sleep quality in the ICU has been reported previously. The effects of noise observed in our study appeared to relate particularly to the use of bedside phones. A potential solution to this problem might be to insist that phones are switched to vibration mode at night. Other noises that affected sleep quality, for example, those from intravenous pump alarms and ventilator alarms have been reported previously to adversely affect sleep. These should be attended to immediately, if they alarm, to minimize noise. Our findings do not support the hypothesis that ICU noise is the most disruptive stimulus for sleep for most ICU patients. This finding contradicts much of the current literature, which suggests that noise is the major ICU factor responsible for sleep disruption., ${ }^{3,16-25-30}$ As suggested before, ${ }^{12}$ noise may cause arousal, but not awakening, leading to sleep fragmentation and poor sleep quality. Patients who were never fully awakened from sleep may not however have been able to recall the etiology of their fragmented sleep.

Our study design had several limitations. Firstly, the study assessed sleep quality and influencing factors subjectively. We were therefore unable to determine the patients true sleep architecture and degree of sleep disruption caused by the various environmental stimuli. Recall bias is another potentially confounding problem for questionnaire studies in general. However, we think this methodological issue is unlikely to have seriously distorted or invalidated our results. Recall bias was examined previously by Freedman and reported not to be a problem over the relatively short recall periods of patient stay in ICU. ${ }^{12}$ Wrist actigraphy is a potentially cheap and non-labor-intensive mode for monitoring sleep wake and agitation, ${ }^{31}$ though it has not yet been fully validated in ICU. ${ }^{32,33}$ Additionally, there may have been a recruitment and selection bias that limits the generalizability of the results to the ICU population as a whole. Only subjects discharged on Monday to Friday mornings from 08:00 to 12:00 were invited to participate, and the sample of 100 patients was mainly a convenience sample. However, most discharges are performed during this time frame. Similarly this study did not include patients who died before their ICU discharge. Finally, the possibility of delirium cannot be ruled out in our patients, although we required orientation to time, place, and person for inclusion in the study. We also screened for dementia by CDR score, which has secondary variables such as judgement and problem solving. We excluded 24 patients based on CDR score $\geq 2$. The possibility of recall bias caused by delirium some time during the acute illnesses cannot be excluded but seems unlikely to have been a major confounder, given the orientation of patients and their low CDR scores.

Data regarding the total doses of medications used were not collected in this study, and it would be a useful in future studies. Similarly, objective noise and light intensity measurements would be a useful addition in future studies.

In conclusion, our results support the hypothesis ${ }^{12-14}$ that interruptions of sleep in the ICU are multifactorial. In addition to previously identified environmental factors, several non-environmental factors, such as prior quality of sleep at home, use of regular sleeping tablets before ICU admission, treatment for hypo-/hyperthyroidism, plus use of benzodiazepines and steroids administration during the ICU stay were associated with self-reported poor quality sleep. Although environmental factors such as telephone noise are important contributors to sleep disruption in the ICU, there are a number of other important 
factors intrinsic to the ICU encounter or intrinsic to the patient that may adversely influence sleep quality in ICU. Patients who have a prior history of sleeping difficulties or who have used hypnotic of other psychotropic drugs may be at particular risk of sleeping poorly in the ICU and should perhaps be the target for special attention to improve their sleep environment.

\section{REFERENCES}

1. Walder $B$, Haase $U$, Rundshagen I. Sleep disturbances in critically ill patients Anaesthesist 2007:56:7-17

2. Parthasarathy S, Tobin MJ. Sleep in the intensive care unit. Intensive Care Med 2004:30:197-206.

3. Aaron J, Carlisle C, Carskadon M, Meyer TJ, Hill NS, Millman RP. Environmental noise as a cause of sleep disruption in an intermediate respiratory care unit. Sleep 1996;19:707-10.

4. Aurell J, Elmquist D. Sleep in the surgical intensive care unit: continuous polygraphic recording in nine patients receiving postoperative care. BMJ 1985;190:1029-32.

5. Broughton R, Baron R. Sleep patterns in the intensive care unit and on the ward after acute myocardial infarction. Electroencephalogr Clin Neurophysiol 1978:45:348-60.

6. Buckle P, Pouliot Z, Millar T, Kerr P, Kryger MH. Polysomnography in acutely ill intensive care unit patients. Chest 1992;102:288-91.

7. Fontaine D. Measurement of nocturnal sleep patterns in trauma patients. Heart Lung 1989;18:402-10.

8. Hilton B. Quantity and quality of patient's sleep and sleep disturbing factors in a respiratory intensive care unit. J Adv Nurs 1976;1:453-68.

9. Richards K, Bairnsfather L. A description of night sleep patterns in the critical care unit. Heart Lung 1988;17:35-42.

10. Orr W, Stahl M. Sleep disturbances after open heart surgery. Am J Cardiol 1977;39:196-201

11. Wallace CJ, Robins J, Alvord LS, Walker JM. The effect of earplugs on sleep measures during exposure to simulated intensive care unit noise. Am J Crit Care 1999:8:210-9.

12. Freedman NS, Kotzer N, Schwab RJ. Patient perception of sleep quality and etiology of sleep disruption in the intensive care unit. Am J Respir Crit Care Med 1999:159:1155-62.

13. Freedman NS, Gazendam J, Levan L, Pack Al, Schwab RJ. Abnormal sleep/ wake cycles and the effect of environmental noise on sleep disruption in the intensive care unit. Am J Respir Crit Care Med 2001;163:451-7.

14. Gabor JY, Cooper AB, Crombach SA, et al. Contribution of the intensive care unit environment to sleep disruption in mechanically ventilated patients and healthy subjects. Am J Respir Crit Care Med 2003;167:708-15.

15. Krachman SL, D'Alonzo GE, Criner GJ. Sleep in the intensive care unit. Chest 1995; 107:1713-20

16. Hilton BA. Quantity and quality of patients' sleep and sleep disturbing factors in a respiratory intensive care unit. J Adv Nurs 1976;1:453-68

17. Morris JC. The Clinical Dementia Rating (CDR): Current version and scoring rules. Neurology 1993:43:2412-4
18. Born J, Zwick A, Roth G, Fehm-Wolfsdorf G, Fehm HL. Differential effects of hydrocortisone, fluocortolone, and aldosterone on nocturnal sleep in humans. Acta Endocrinol (Copenh) 1987;116:129-37.

19. Wolkowitz OM, Rubinow D, Doran AR, et al. Prednisone effects on neurochemistry and behavior: preliminary findings. Arch Gen Psychiatry 1990;47:963-8.

20. Borbely AA, Mattmann P, Loepfe M, Strauch I, Lehmann D. Effect of benzodiazepine hypnotics on all-night sleep EEG spectra. Hum Neurobiol 1985;4:189-94.

21. Trompeo AC, Vidi Y, Locane MD, et al. Sleep disturbances in the critically ill patients: role of delirium and sedative agents. Minerva Anestesiol 2011;77:604-12

22. Bonnet $M$. The effect of sleep fragmentation on sleep and performance in younger and older subjects. Neurobiol Aging 1989;10:21-5.

23. Bonnet M. Infrequent periodic sleep disruption: effects on sleep, performance and mood. Physiol Behav 1989;45:1049-55.

24. O'Donnell D, Silva EJ, Munch M, et al. Comparison of subjective and objective assessments of sleep in healthy older subjects without sleep complaints. J Sleep Res 2009;18:254-63.

25. Falk S, Woods N. Hospital noise levels and potential health hazards. N Eng J Med 1973;289:774

26. Meyer T, Eveloff S, Bauer M, et al. Adverse environmental conditions in the respiratory and medical ICU settings. Chest 1977;105:1211-6.

27. Redding J, Hargest T, Minsky S. How noisy is intensive care? Crit Care Med 1977;5:275-6.

28. Easton C, MacKenzie F. Sensory-perceptual alterations: delirium in the intensive care unit. Heart Lung 1988;17:229.

29. Snyder-Halpern R. The effect of critical care noise on patient sleep cycles. Crit Care Q 1985;7:41.

30. Weber R, Soak M, Bolender B. The intensive care unit syndrome: causes, treatment and prevention. Drug Intell Clin Pharm 1985;19:13.

31. Grap MJ, Borchers CT, Munro CL, et al. Actigraphy in the critically ill: correlation with activity, agitation, and sedation. Am J Crit Care 2005;14:52-60

32. Beecroft JM, Ward M, Younes M, Crombach S, Smith O, Hanly PJ. Sleep monitoring in the intensive care unit: comparison of nurse assessment, actigraphy and polysomnography. Intensive Care Med 2008;34:2076-83

33. Watson PL. Measuring sleep in critically ill patients: beware the pitfalls. Crit Care 2007;11:159.

\section{SUBMISSION \& CORRESPONDENCE INFORMATION}

Submitted for publication October, 2011

Submitted in final revised form January, 2012

Accepted for publication February, 2012

Address correspondence to: Shailesh Bihari, Department of Intensive and Critical Care Unit Flinders Medical Centre, Bedford Park South Australia 5042; Tel: 00618 82044247; Fax: 0061882045751

\section{DISCLOSURE STATEMENT}

This was not an industry supported study. The authors have indicated no financial conflicts of interest. 